\title{
PÓS-GRADUAÇÃO EM EDUCAÇÃO FíSICA NO BRASIL: O FENÔMENO DA HIPERPRODUTIVIDADE E FORMAÇÃO CULTURAL
}

Elenor Kunz *

\section{RESUMO}

Embora o problema da corrida atrás de pontos no currículo Lattes para estar bem ranqueado na CAPES, por parte de pesquisadores e programas de pós-graduação no Brasil, esteja alcançando dimensões absurdas, poucos, até agora, se atreveram a fazer uma análise mais crítica deste problema entre nós, especialmente, no que tange a falta de responsabilidade das pesquisas atuais com relação à relevância sociocultural local da produção científica. Este artigo levanta alguns problemas nesse sentido, questionando a pós-graduação em Educação Física no País e sua corrida desenfreada atrás de publicações internacionais que mantém programas e pesquisadores ativos perante a CAPES e apenas isso.

Palavras-chave: Pós-graduação. Produção Científica. Formação Cultural.

\section{INTRODUÇÃO}

A pós-graduação brasileira de Educação Física com seus programas de Mestrado e Doutorado vem conseguindo, pelo menos em algumas áreas do conhecimento, acompanhar o aumento vertiginoso da produção científica, em forma de publicação de artigos nacionais e internacionais, dos programas mais produtivos e melhor avaliados pela Capes no País. Esse avanço da "produção científica" não significa necessariamente que a área como um todo tenha alcançado em grande desenvolvimento científico nos últimos anos.

A pesquisa de Manoel e Carvalho (2011) mostra que, pela caracterização acadêmica da pós-graduação em Educação Física no Brasil em três grandes áreas. Biodinâmica, sociocultural e pedagógica, somente a primeira cresceu e se desenvolveu de forma mais expressiva.

Os autores apontam que essa caracterização da área em subáreas apresenta a biodinâmica com suas atividades de pesquisa a partir de disciplinas que envolvem a bioquímica do exercício, a biomecânica, a fisiologia do exercício, o controle motor, a aprendizagem e desenvolvimento motor, entre outras. Já a subárea sociocultural apresenta suas atividades de pesquisa com as temáticas do esporte, práticas corporais e atividades físicas de perspectiva sociológica, antropológica, histórica ou filosófica. Por último, a subárea pedagógica pesquisa temáticas relacionadas à Educação e a Educação Física, como a questão da formação profissional, desenvolvimento curricular, métodos 
de ensino e aprendizagem, a pedagogia dos esportes, além de fundamentos teórico-metodológicos que envolvem aspectos sociopolíticos, filosófico, pedagógicos e culturais da educação.

Segundo Manoel e Carvalho (2011) ainda, foi a partir de 1998 que a CAPES se vincula a um sistema internacional de avaliação da produtividade científica dos pesquisadores brasileiros dos programas de pós-graduação. A partir de então as revistas científicas de cada área começam a ser avaliadas pelo seu impacto entre os pesquisadores e comunidades científicas. Comentam os autores que os "artigos científicos tornaram-se os itens mais valorizados na avaliação, sendo classificados de acordo com os periódicos em que foram publicados, os quais, por sua vez, eram julgados com base em indicadores elaborados pelo InstituteofScientific/nformation (ISI)"

Começa a partir daí então uma corrida para publicações nas chamadas revistas internacionais e reconhecidas pelos indexadores, como a acima mencionado (outras bases de indexação são compostos pelas MEDLINE, ERIC, Psychinfo, SciELO e LILACS). Interessante notar ainda, que a maioria dessas bases indexadoras são de origem norte americana e, então, é para lá que se devem dirigir a maioria dos artigos para conquistar as tais publicações internacionais.

Assim, para o sistema de pós-graduação no Brasil a "produção científica" é medida pelo numero de artigos publicados em revistas nacionais e internacionais. Sem entrar na polêmica maior de como se mede a qualidade científica dos artigos por esses indexadores, fica evidente que algumas áreas são privilegiadas. Apontam Manoel e Carvalho (2011) que a área mais privilegiada na Educação Física é a biológica.

A maioria dos periódicos indexados no ISI é de orientação biológica, em detrimento daqueles de orientação sociocultural (HOPKINS, 2001). O maior número de periódicos nas ciências naturais faz com que seus fatores de impacto sejam maiores em relação aos das ciências sociais e humanas (WATERS, 2006); na educação física, também não é diferente (CARVALHO; MANOEL, 2006; RODRIGUES, 2007).

Em resumo esse é o quadro da pós-graduação brasileira em Educação Física, ou seja: 
1. O pesquisador/orientador desses programas precisa se lançar de forma desenfreada na busca de pontos na Capes para o seu currículo a fim de atingir o patamar mínimo e continuar na pesquisa e na orientação de mestres e doutores.

2. O alcance desses pontos é favorecido nas áreas biológicas, ou seja, a subárea biodinâmica como visto acima.

3. Orientadores passam a ser "Gerenciadores de artigos" eles próprios pouco ou nada produzem, mas conseguem "gerenciar" as produções de seus orientandos de tal forma que consigam boas publicações e os tão almejados pontos na Capes.

4. A relevância social das pesquisas para a realidade da Educação Física brasileira não interessa mais, ao ponto de muitos pesquisadores brasileiros hierarquizados como "pesquisadores internacionais", serem na maioria das vezes, totalmente desconhecidos da maioria dos profissionais da Educação Física, ou melhor, por aqueles que deveriam ser os principais beneficiados de suas pesquisas.

Na sequência, tentarei discutir com certa radicalidade crítica o que pode acontecer quando se desenvolvem programas de pós-graduação no formato do que denomino de: "Fabrica de Textos e Empresa de Publicações"

\section{Da Semi-Formação para a Sem-Formação}

Pesquisas no Brasil são realizadas hegemonicamente nas universidades. Universidades pertencem ao sistema educacional brasileiro, logo compromissado com a Educação e Formação Cultural do cidadão.

Theodor Adorno, da chamada teoria crítica da sociedade apresentou já na década de 60 uma análise critica sobre o que denominou de crise na formação cultural. Neste sentido é preciso explicar que a formação a que se referia é aquela que, embora proposta pelo sistema educacional vai muito além, melhor dizendo, a Educação sempre teve o compromisso de não apenas formar cidadãos para o mundo do trabalho mas pessoas com capacidade de autonomia e crítica. Cidadãos emancipados e críticos apresentam uma cultura abrangente e de forma não apenas superficial, eles conseguem ver além das aparências e entender as complexas relações socioculturais de toda trama da existência humana. 
Para Theodor Adorno (1996) esta forma de educação e formação humana não tem mais possibilidades de se realizar nas sociedades atuais. $O$ que ocorre é uma semiformação cultural (Halbbildung). Uma educação e formação cultural onde impera a aquisição rápida de informações, desprezando completamente os bens culturais que a humanidade produziu por séculos, "uma formação que se esquece disso, que descansa em si mesma e absolutiza-se, acaba por se converter em semiformação" (390).

Portanto, num mundo, como atualmente muito mais do que na década de 60 conforme previsões de Adorno, dominado pela informação, a pressa e 0 trabalho produtivo para atender mercados é cada vez mais difícil a possibilidade de uma formação mais ampla do ponto de vista sociocultural, artístico, filosófico e espiritual. Somos dominados pela era denominada "Gestão do Conhecimento" onde conhecimento significa informação. Informação notadamente nada esclarecedora e muito menos formadora de personalidades criticas e emancipadas.

Em assim sendo já podemos estar perdendo até mesmo a semiformação e então não resta mais nada, entramos na era do mundo "semformação", conforme nos alerta o filósofo Austríaco Konrad P. Liessman (2008) em sua obra "Teoria da Semformação" (Theorie der Unbildung). Segundo Liessman, a semiformação ainda se dirigia para a crítica da formação/educação que atualmente não se legitima mais. Isso porque a fragmentação, particularização e ao mesmo tempo a disponibilidade universal do saber não permitem mais uma ideia de formação/educação com nexos, com relações, nem mesmo as de caráter crítico. Por isso o problema de nossa época não é mais a semiformação cultural, mas sim a total ausência de qualquer ideia normativa sobre formação, onde ainda seria possível a interpretação de uma semiformação.

Para interpretar melhor isso temos a entender que uma vida numa sociedade "semformação" não significa que se possa pensar na ausência total de conhecimentos. Os conhecimentos continuam se avolumando, porém apenas em forma de informações, que pouco favorecem ao esclarecimento mais crítico da realidade e dos fatos.

Nas próprias pesquisas que podem ser lidas nas tais revistas indexadas atualmente nota-se que há sérios problemas quando tentam tratar de sentidos e significados do conhecimento e suas relações com a compreensão da 
realidade pesquisada. Trata-se de produções de conhecimentos em que o mais importante da pesquisa é o lugar onde se pode disponibilizar tal conhecimento, as chamadas revistas que contemplam com uma melhor pontuação na Capes.

Vivemos numa Sociedade dita de conhecimento, as grandes empresas falam muito e oferecem cursos para a chamada era da "Gestão do Conhecimento", mas é de informação que se trata. Profissional em qualquer área de melhor reputação é aquele que consegue guardar um maior número de informações e substituí-las rapidamente se a profissão ou o mercado exige. Porém, ter muita informação não significa ter um real e profundo conhecimento sobre algo. A informação em si não tem nada a ver com Saber e Conhecer. Informação é qualquer diferença que num Evento futuro faz a diferença.

Saber e Conhecer é mais do que ter um grande numero de informações. O saber permite filtrar entre muitas informações, aquelas que têm valor, saber é uma forma de nos introduzirmos no mundo, pelo reconhecer, compreender, interpretar. O Saber pode levar a um conhecimento crítico e emancipado da realidade.

Ao contrário da informação que apresenta apenas uma interpretação de dados em vistas a uma perspectiva de ação, para interferir numa realidade dada, é possível descrever o saber como uma possibilidade de interpretação de dados e fatos em vistas as suas relações causais, seus nexos mais amplos com a realidade e sua consistência interna.

$\mathrm{Na}$ moda antiga poderíamos dizer que o saber existe lá onde algo precisa ser esclarecido e compreendido. O saber se referencia a um conhecimento, onde a questão central é a busca da verdade.

Nunca foi tão fácil penetrar em qualquer área de conhecimento ou fenômenos e se informar, como na atualidade. Praticamente qualquer disciplina científica expõe seus saberes científicos de forma pública, senão por revistas não especializadas ou por internet. Todas as principais revistas da área de Educação Física, estão disponíveis on-line. No entanto não é possível resistir à impressão de que as possibilidades quantitativas desse conhecimento se comportam proporcionalmente de forma equivocada sobre aquilo que realmente foi trazido ao conhecimento. Ou seja, é justamente essa facilidade de acesso aos conhecimentos que sabota uma formação para um saber. Sem 
processar o saber e a aquisição de um compreender mais global, as informações ficam apenas na sua superficialidade.

Quando trabalhamos na perspectiva do Saber e Conhecer, estamos sempre procurando, em verdade, respostas para as questões do o que e por que algo existe e nos intriga. Por isso o Saber e Conhecer não são simples produtos de consumo. Para Liessmann (2008), as instituições de formação cultural não podem se prestar a ser apenas empresas prestadoras de serviço ao mercado consumidor.

Já demos a entender que o Saber é algo que transcende o conhecimento objetivo e o acesso às informações. Uma pessoa que Sabe não pode ser avaliada apenas por aquilo que ela tem na cabeça, ou seja, na memória, por mais estudada que seja. Os dados armazenados na memória sejam lá do que for ou de que importância possam ter para o momento, ainda não é um Saber. Portanto, quem cataloga inúmeras informações na memória, ou sabe resolver facilmente um problema que exige informações guardadas,não pode, apenas por isso, ser considerada uma pessoa que tenha um Saber. Porém, com essa capacidade de memória, existe a possibilidade de transformação para um verdadeiro saber por uma pessoa contemplada com esse potencial, ou seja,na medida em que ela, com essas unidades de memória e conceitos souber fazer relações lógicas com critérios consistentes, de forma que resulte em conexões com sentido e possivelmente ser, inclusive, comprovadas. Dados históricos, por exemplo, que não forem vinculados as ciências históricas e seus contextos, mas simplesmente agrupados por afinidade política ou emocional, não podem resultar num saber e sim numa ideologia.

Enfim, como já conhecido na metafísica aristotélica: Todo Ser Humano tem por natureza um grande desejo de Saber, parece que esse saber vem se transformando em Informação.

Há muito que em nossas escolas estamos inclinados a ensinar o aprender a aprender, desconsiderando totalmente o querer saber dos alunos. $E$, embora não haja um aprender sem conteúdos, aprender a aprender apenas para a decoreba de informações promove no aluno o adormecer de seu grande desejo de querer conhecer e saber. 


\section{Pós-Graduação e Pesquisa}

Vivemos, no contexto acadêmico da pós-graduação, um clima de otimismo ingênuo, como caracteriza Ouriques (2011) devido ao grande e vertiginoso aumento das produções científicas e tecnológicas no País dos últimos anos. Esse "avanço", julgado pelos órgãos competentes pelo fato da grande performance dos pesquisadores em publicações internacionais, na verdade, ainda não pode significar desenvolvimento científico para o País e muito menos para as áreas envolvidas como é o caso que estamos tratando, a Educação Física.

$\mathrm{Na}$ perspectiva do desenvolvimento acelerado ou da pressa pelo conhecimento científico e tecnológico e apresentado nos principais canais de divulgação, é possível concluir, conforme Liessmann (2008), que não é a sociedade do conhecimento que estásubstituindo a sociedade industrial moderna, mas, ao contrário, o Conhecimento e o Saber estão sendo, em uma velocidade assustadora, industrializados.

Assim como na produção industrial que segue a lógica da produção mecanizada e automatizada de idênticos produtos com idênticas condições e meios, também na produção científica especialmente em pesquisas das ciências da natureza, no nosso caso na subárea da biodinâmica, tudo parece se encaminhar como na lógica da produção industrial. Ou seja, os experimentos visamalcançar resultados semelhantes a partir de métodos semelhantes e sob condições também semelhantes. Assim, pode se dizer que um experimento científico é bem sucedido quando, pelo menos em princípio, ele pode ser reproduzido pelos mesmos métodos e nas mesmas condições objetivas.

Manoel e Carvalho (2011) se referem aos problemas da pesquisa em Educação Física no Brasil, como o excesso de concentração nas ciências da Natureza, de forma idêntica aos EUA, quando mencionam Vertinsky (2009) afirmando que "a crescente presença da cinesiologia cria um movimento para privilegiar a pesquisa quantitativa com ênfase em fenômenos naturais e na identificação dos mecanismos subjacentes a eles. Em contraposição, as preocupações com fenômenos sociais, pesquisas qualitativas e estudos interpretativos têm sido postas de lado." 
Para as ciências da natureza, portanto, todo conhecimento fora dos padrões por eles mesmos instituídos, ou seja, que não correspondam as suas metodologias cientificamente validadas não são absolutamente reconhecidos. Assim, por exemplo, muitos cientistas do passado e grandes descobridores científicos, hoje não seriam reconhecidos como cientistas, muito menos pesquisadores da Capes, pois Ihes faltariam muitos pontos para serem docentes em um programa de pós-graduação.

Lembramos, para a sequencia dessa reflexão crítica uma afirmação de Nietzsche "Aquiloque todo mundo sabe, todo mundo esquece logo". Se conhecimento é poder ele não está lá onde todo mundo tem acesso.

A formação cultural e que hoje se encontra cada vez mais ausente nos meios escolares e acadêmicos, conforme acima, deveria se configurar num programa para transformar o Ser Humano, pelo trabalho intelectual, para potencializar qualidades que o capacitassem a um compreender a si mesmo e o mundo, ou seja, para um acesso paradigmático ao saber sobre si mesmo e o mundo assim como o entendimento significativo desse saber. Segundo Liessmann (2008), já para Hegel a formação cultural não era nada externo ao espírito, mas o meio através do qual o espírito se realiza. "O espírito para Hegel é o quese forma e apenas o que se forma pode ser entendido como espírito. Esse conceito de espírito, intelecto, foi de certo modo eliminado nas ciências modernas e nos conceitos culturais, o que também significa uma desistência com relação à formação cultural".

Já a muito tempo que escola e universidade não trabalham mais para uma educação no sentido da formação cultural mais ampla mas apenas para a aprendizagem, significando dizer para a decoreba de informações.

Escola, do grego schola, significava uma "pausa ao trabalho", portanto um lugar da liberdade, para ser livre da pressão de produzir algo útil, ou algo que tem relevância prática. Escola como lugar do Lazer e do Prazer. Uma escola que deixou de ser esse lugar, do lazer, concentração, da contemplação, deixou de ser escola. Tornou-se uma instituição com escassez de vida. Lugar onde crianças são treinadas para as competências, definidas por adultos. A formação cultural que ainda se pode definir teoricamente como um entendimento um debate vivo do espírito/intelecto consigo mesmo e com o mundo é hoje na escola transferido para uma acumulação de bens culturais 
que devem ser adquiridos e consumidos sem mesmo poderem ser assimilados. É isso que Adorno (1966) quis dizer com Semiformação Cultural. No entanto, Liessmann (2008), afirma que hoje já vivemos a era da "não formação", ou "sem formação", onde a Ideia de formação sob todos os pontos de vista desapareceu e sua função normativa e regulativa foi absolutamente abandonada.

A ausência de uma formação cultural é visível hoje na escola e na universidade; não que faltem conhecimentos, mas ali ocorre somente 0 consumo de conhecimentos, a decoreba de informações.

Temas como autonomia do sujeito, singularidades individuais ou emancipação humana ficaram sem sentido nestas instituições, pela falta de possibilidades formativas. Liessmann (2008) afirma que "Sem Formação" não significa deficiência intelectual, falta de informações e nem mesmo defeitos na competência cognitiva, mas desistência geral de querer COMPREENDER. Sempre que se fala de conhecer, saber, informar, esquece-se do COMPREENDER.

O que é uma boa Universidade: avaliar e estar no topo da lista, nos primeiros postos do ranking da Capes para Pós-Graduação. Em que consiste a dignidade científica? Publicar nas melhores revistas internacionais, estar na lista dos melhores. Nunca a coisa em si é objeto de reflexão, mas o lugar na lista, no ranking. Avaliar significa cada vez mais quantificar. A questão crucial sobre o que se está pesquisando/escrevendo é substituída pela pergunta qual o Qualis da revista em que se publica. Os próprios problemas de pesquisa são ultimamente escolhidos por esta questão, ou seja, para mais pontos na Capes. Até mesmo a autoridade e os critérios de quem estabelece o ranking das revistas nunca é discutido.

Assim, o problema do Sentido, da função e relevância social das pesquisas científicas, bem como as questões sobre que conhecimento e para queformação não fazem mais parte dessas novas preocupações científicas.

Consta que Kant, um dos maiores filósofos até hoje, nunca viajou, não fez experiências acadêmicas internacionais e logo após o primeiro emprego na Universidade de Köningsberg, parou dez anos de publicar.

É difícil dizer se as avaliações (Capes) realmente avaliam o que dizem avaliar. Mas conseguem apenas alcançar sua meta de transformar 
gradualmente uma ciência livre em uma instituição prestadora de serviços sem liberdade.

Avaliações existem para a formação dos tais indicadores de qualidade: índices, estatísticas, sistema de pontos, fatores de impacto, quotas de crescimento, custos e benefícios, financiamentos, etc.

As avaliações sistemáticas via Capes primeiro produzem a realidade que depois irão avaliar, pois, na medida em que se sabe o que vai ser avaliado, se cumpre a expectativa. Se é preciso publicar mais, então publicamos mais, se precisamos publicações A1, A2 procuramos as revistas que oferecem essa possibilidade, se precisamos de financiamentos vamos a busca, são necessário bolsas idem.

Portanto as avaliações não estão em condições de avaliar a qualidade, a teimosia das produções científicas que podem resultar em grandes avanços do conhecimento. Desta forma não é o conhecimento científico que cresce, mas a organização burocrática.

A dominância da língua Inglesa como linguagem científica é outro recurso de elitização do conhecimento para, na maioria das vezes, encobrir falta de sentido. A elite científica não se destaca mais apenas por sua criatividade e originalidade, mas pelo domínio da língua inglesa. Para Liessmann (2008) o filósofo alemão Nietzsche escreveu, "os dois povos que produziram os maiores estilos literários, não conheciam língua estrangeira: os gregos e os franceses".

A área pedagógica da EF passa por um dilema, sua excelência científica é da mesma forma avaliada pelos indicadores e os padrões de qualidade nacional e internacional. Assim, ao mesmo tempo em que precisam demonstrar sua validade através de publicações, precisam se ajustar as "qualidades requeridas" para a publicação. A área pedagógica na Educação Física brasileira, pode produzir e publicar o que quiser, mas jamais conseguirá alcançar o padrão de qualidade das áreas que se utilizam das ciências biológicas e da natureza, ou tecnológicas. 


\section{CONSIDERAÇÕES FINAIS}

Manoel e Carvalho (2011) em sua pesquisa sobre os programas de pósgraduação em Educação Física no Brasil e nos EUA identificaram que no Brasil os programas de pós-graduação são "fortemente orientados pelo número de artigos publicados em periódicos com fator de impacto (indexados em uma das bases $\mid \mathrm{SI}$ ) dividido pelo número de docentes do programa". A pesquisa confirma também que a publicação em periódicos brasileiros "é desvalorizada independentemente de seu impacto científico e de sua importância social, considerando as necessidades nacionais, regionais e locais". O mesmo acontecendo com os Livros.

Assim, o gerenciamento da produção de conhecimentos nos meios acadêmicos vem obedecendo a essa lógica, ou seja, produções apressadas, sem a menor preocupação com as necessidades regionais ou nacionais, estabelecendo diálogos apenas com pesquisadores que investigam a mesma realidade, a mesma especificidade, notadamente de natureza biológica da Educação Física. Isso vai gradativamente eliminando uma área que sempre foi considerada de máxima importância pela Educação Física: a subárea pedagógica.

Já em 2006, segundo informam Manoel e Carvalho (2011), dos 860 projetos de pesquisa cadastrados nos programas de Pós-Graduação em Educação Física, 67,4\% eram da subárea biodinâmica. Juntas, as subáreas sociocultural e pedagógica têm pouco mais de $30 \%$ do total de projetos de pesquisa.

Também é conhecido o fato de que muitos profissionais pesquisadores de Educação Física que atuavam nos programas de Pós-graduação nas subáreas sociocultural e pedagógica e de grande reconhecimento nacional devido ao impacto de suas produções científicas, notadamente em forma livros, migraram para outros programas de Pós-Graduação como os da Educação, por não suportarem a "elevação sarrafo" para as produções científicas na área. Porém, essa medida só acontece para que a subárea hegemônica da grande área possa manter o domínio do conhecimento.

Isso são alguns reflexos negativos imediatos que podemos sentir com esse "espetacular aumento da produção científica" em nosso meio e em nossa 
área de conhecimentos. Os piores reflexos talvez ainda estejam por vir, ou então, ainda não podem ser percebidos como nefastos ou catastróficos.

Para concluir, apenas à guisa de reflexão, um pequeno exemplo de uma possibilidade catastrófica e que com toda certeza remete ao conceito acima discutido sobre a semiformação cultural ou até mesmo a "semformação cultural”: um professor universitário de graduação e pós-graduação, portanto pesquisador das melhores universidades brasileiras, hoje apresenta seu Saber a seus alunos, ou mesmo em Congressos e similares, através de seu Laptop pela projeção de um PowerPoint. Essa tecnologia representa o símbolo maior de uma semi ou semformação cultural. Através dela pode-se apresentar inúmeras informações a partir de frases simples, conceitos superficiais, quadros, figuras, gráficos e tudo mais para uma leitura rápida e superficial não permitido, na maioria das vezes, reflexões mais profundas e muito menos discussões de conteúdo. Quando a dominação tecnológica substitui o Saber e o poder da palavra então também o pensamento pode ser substituído pela memória e as formulações lógicas de um programa de computador previamente estabelecido para as finalidades científicas pretendidas.

\section{REFERÊNCIAS}

Adorno, Th. - Teoria da Semicultura. In: Educação e Sociedade no. 56. Campinas, Unicamp, 1996.

Carvalho, I.M./Manoel, E.J. -Pós-Graduação na Educação Física Brasileira: a atração (fatal) pela biodinâmica. In: Educação e Pesquisa. vol.37 no.2 São Paulo/ago. 2011.

Liessmann, P. K. - Theorie der Unbildung. Die Irrtümer der Wissensgesellschaft. Wien, Paul ZsolnayVerlag, 2008.

Ouriques, N. - Ciência e Pós-graduação na Universidade Brasileira. In: Rampinelli, W./Ouriques, N. - Crítica da Razão Acadêmica. Florianópolis, Insular, 2011. 


\begin{abstract}
.
POSTGRADUATE PROGRAMS IN PHYSICAL EDUCATION IN BRAZIL: THE PHENOMENON OF HYPER-PRODUCTIVITY AND CULTURAL FORMATIN
\end{abstract}

\title{
ABSTRACT
}

Although the problem of looking after points to gain in order to upgrade the Lattes CV and be well ranked at the Capes of researchers and post-graduation programs in Brazil is reaching outrageous levels, just a few people, until now, have dared to make a more critical analysis of the this problem that exists among us, specially in what concerns the lack of responsibility of the curent researches related to the socio-cultural level of the local scientific researches. This article raises some of the problems on this aspect, questioning the post-graduation in physical education in the country and the uncontrolled rush of the people into publishing their papers internationally, which is the only thing that mantains programs and researchers actives on Capes.

Keywords: Post-Graduate Program. Scientific production.Cultural formation.

\begin{tabular}{lrrrrrrr}
\hline POSTGRADO & EN EDUCACION & F'SICA & EN & BRASIL: & EL & FENOMENO & DE \\
HIPERPRODUCTIVIDAD Y FORMACIÓN CULTURAL & & & & &
\end{tabular}

\section{RESUMEN}

La cuestión de la carrera por puntos para estar bien clasificados en el currículo Lattes - CAPES per investigadores y los programas de postgrado en Brasil están alcanzando dimensiones absurdas. Pocos se atrevieron a hacer un análisis más crítico de esta cuestión entre nosotros, sobre todo en relación con la falta de responsabilidad y importancia sociocultural en la producción científica actual local. Este artículo plantea algunos problemas en este sentido, cuestionando el postgrado en educación física en el país y la desenfrenada carrera detrás de publicaciones internacionales para mantener programas y investigadores activos en CAPES y sólo eso.

Palabras clave: Postgrado. Producción científica. Formación cultural.

Endereço para correspondência: elenkunz@terra.com.br 